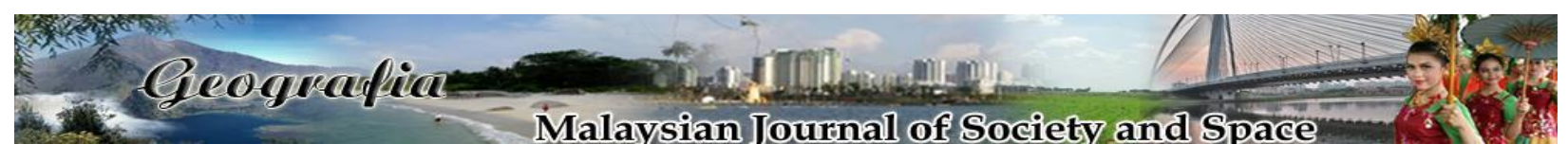

\title{
Fear towards insects and other arthropods: A cross sectional study in a Malaysian university
}

\author{
Aishah Hani Azil ${ }^{1}$, Mohd Adnan Yakub², Norhaty Hassan³ ${ }^{3}$ Shalisah Sharip² \\ ${ }^{1}$ Department of Parasitology and Medical Entomology, Faculty of Medicine, \\ Universiti Kebangsaan Malaysia \\ ${ }^{2}$ Department of Psychiatry, Faculty of Medicine, Universiti Kebangsaan Malaysia \\ ${ }^{3}$ Department of Nursing, Faculty of Medicine, Universiti Kebangsaan Malaysia \\ Corresponding author: Shalisah Sharip (email: shalisah@ppukm.ukm.edu.my)
}

Received: 14 September 2020; Accepted: 02 February 2021; Published: 27 February 2021

\begin{abstract}
Insects and other arthropods can elicit fear and disgust in certain individuals and communities which is yet to be explored in Malaysia. Therefore, we aimed to determine the prevalence of fear and disgust toward varied arthropods and compare the level of emotions between female and male respondents and the different arthropod types. A cross-sectional survey using a new designed arthropods survey was performed among 224 undergraduate students in Universiti Kebangsaan Malaysia. Based on our study, more than half of the respondents feared scorpion, wasp, centipede, bee, blister beetle and cockroach. Meanwhile, more than half of the respondents reported disgust toward maggot, cockroach, caterpillar, centipede, sago larvae and head lice. Female students who formed the majority of respondents reported higher fear and disgust toward the top-fifteen chosen insects. The most feared arthropod is the scorpion, while maggot (i.e. fly larvae) is the most disgusted arthropod. Statistically significant differences of fear were found between female and male respondents toward most arthropods, whereas no significant differences were found between genders for disgust toward most arthropods. In addition, previous history of spider bite is significantly associated with fear of spiders. This study revealed fear of arthropods is prevalent among university students in Malaysia. Persistent fear toward arthropods can lead to entomophobia, a specific phobia that may require intervention by health professionals.
\end{abstract}

Keywords: arthropods, disgust, fear, gender, insects

\section{Introduction}

Arthropods (phylum Arthropoda) are living creatures important for maintaining biodiversity. They are invertebrates characterised by having an outer body called exoskeleton, segmented and bilateral symmetrical body and jointed appendages. The large phylum Arthropoda comprises of four extant subphylums: Hexapoda (insects and springtails), Chelicerata (such as spiders, 
scorpions, mites and ticks), Myriapoda (millipedes and centipedes) and Crustacea (such as crabs and prawns) (Gerozisis, Hadlington, \& Staunton, 2014).

It has been acknowledged that insects (Class Insecta) are the largest class of the phylum Arthropoda and the most diverse group of animals found in nearly every environment (Jun et al., 2016). With an estimated between two to six million species, only one million species have been described (Gullan \& Cranston, 2014). Examples of insects are mosquitoes, flies, ants, bees, wasps, butterflies, moths, beetles and many more. More importantly, evaluation of insects and plants species are influenced by biogeography (Pato et al., 2019) and ecological factors (Vidal et al., 2019). Many insects and plants are found in tropical forests and low altitudes, while much lesser insects and plants are seen in Arctic region or higher altitudes (Gaston, 1992; Gullan \& Cranston, 2014). Environmental fluctuations specifically climate alter genetic and phenotypic (e.g., morphology and behavior) variations among insect populations (Pato et al., 2019).

Although some arthropods are found in the majority of countries, some species are only found in certain regions; hence different countries have different unique arthropod species. Therefore, human-arthropod interactions differ between environments and types of arthropods that humans encounter. These interactions can be beneficial (for example, rearing honey bees for honey) or harmful (for example, injury caused by arthropod bites or stings). In the case of fear toward arthropods, it can serve both purposes. It is beneficial when the fearful person avoids venomous arthropods, thus preventing them from being bitten. It can be harmful, however, when the fear starts to affect quality of life and prevent one from going to environments where arthropods live.

\section{Literature Review}

Fear and disgust are two emotions experienced by human beings universally. Disgust is characterised by particular facial expression and action followed with lowered blood pressure, lowered galvanic skin response, and nausea. When an individual is feeling fear, activity in preparation for fight or flight is heightened, while suspension of activity is associated with feeling disgust (Phillips et al., 1998).

Fear of insects and insect-borne diseases is no laughing matter. Many studies have been conducted to examine factors that contribute to fear of animal with little information on insects or bugs. Perception to animal as dangerous, high disgust sensitivity toward animal as well as environmental and genetic factors have been known to influence fear of animal (Armfield, 2007; Breed \& Sanchez, 2010; Davey, 1993). Davey (2008) stated that disgust sensitivity is an important factor in generating fear to fear-relevant animals, but also a high possibility of fear to novel animals (Davey, 1993). Furthermore, some insects can induce strong emotional reactions (Jun et al., 2016). Fear of Zika, a mosquito-borne disease, was almost on par with fear of disasters such as forest fire and terrorist attacks (Yang et al., 2018).

Diseases can also be transmitted by insects and other arthropods that may produce a wide range of effects on human health and well-being (Burgess \& Cowan, 1993). Mosquitoes can also carry malaria parasites and yellow fever viruses, deer ticks can carry Lyme disease, and flies and cockroaches can transmit pathogens. Knowing these facts, some individuals with high vulnerability to anxiety may develop fear of being contaminated by insects despite low possibility of contamination. Also, individuals experiencing fear of infestation believe that they are infested with insects or bugs. This is associated with a severe condition known as delusions of parasitosis 
(Berenger \& Parola, 2016; Goddard, 2008; Özer, 2005; Rao, 2017; Trabert, 1995). Previous bites or stings experienced by oneself or experience of watching parents' or others' fearful reactions during childhood can build up to entomophobia (Hardy, 1988; Schönfelder \& Bogner, 2017). Such incidents might entail medical conditions that contribute to development of fear, phobia or anxiety as exemplified by the experience of anaphylaxis by some individuals who had bee stings (Nowak et al., 2015; Roberts-Thomson, et al., 1985). This type of phobia is strongly associated with density and size of insects (Firoozfar et al., 2012) warranting further investigations on phobia toward different types of arthropods.

Recently many studies were conducted looking at the potentiality of insects as protein food. Urbanisation and globalisation push toward a change in diet at a worldwide level with increasing population growth (Cavallo \& Materia, 2018). Edible insects as food for protein is seen in many Asian countries such as Thailand and China (Chen et al., 2009; Hanboonsong, 2010) but not in most Western countries (Cavallo \& Materia, 2018) due to feeling disgust toward insects (La Barbera et al., 2018). Despite that, feeling disgust helps individual to avoid infectious diseases but also plays an underappreciated role in anxieties and phobias such as obsessive compulsive disorder, social phobia and post-traumatic stress syndromes (Curtis, 2011).

Life as university students sometimes expose the students to encounter the things that they fear or arouse phobia in them. For example, having to perform dissection on small animals, enrolling in an entomology course, having a field trip to the forest or any insect-infested area or having to deal with insect pests as experts in agriculture (Hayati \& Minaei, 2015). Lack of understanding from lecturers and peers could worsen the situation because this will hinder the phobic students from getting the appropriate diagnosis and therapy. Extreme fear toward snakes or spiders has been reported to reduce cognitive performance (Okon-Singer et al., 2011) which is truly worrying if experienced by university students. Therefore, it is pivotal for us to learn how common fear of arthropods is and type of arthropods feared by student populations.

Literature review shows that studies investigating the effects of insects and other arthropods on inducing fear or discomfort in healthy populations specifically in Asian countries are still scarce. Furthermore, no literature has stated such fear among clinical population. A few emerging studies had been conducted by Iranian researchers whereby the study determined the prevalence of entomophobia among students (Hayati \& Minaei, 2015; Shahriari-Namadi, Tabatabaei, \& Soltani, 2018), knowledge and practice about entomophobia (Firoozfar et al., 2012). To the best of our knowledge, this is the first study to be conducted to research on fear of arthropods in Malaysia. Therefore, we aimed at (a) determining the prevalence of fear and disgust toward insects and other arthropods and (b) determining whether there are differences between genders for fear or disgust toward insects and other arthropods among students of Universiti Kebangsaan Malaysia (UKM). We also would like to determine whether there is significant difference between rural or urban residents and fear of arthropods.

\section{Method and study area}

This is a cross-sectional study conducted by recruiting undergraduate UKM students using convenience sampling (Bangi and Cheras Campus) on those who were willing to participate in the study. Healthy respondents were included if they are aged 18 and above and excluded if they were uncooperative and/or unable to communicate well in English and Malay. Participants who gave consent were asked to complete the demography survey and fear of arthropods survey. This study 
was approved by the Human Research Ethics Committee of Universiti Kebangsaan Malaysia (Ethics Committee/Irb Ref No: UKM PPI/111/8/JEP-2019-701. Date of approval: 14 November 2019).

A new arthropods survey was created. The survey items were derived from the fear survey schedule (Geer, 1965) and literature reviews on fear of insects (Lockwood, 2013; Marks, 1978, 1987; Rubin et al., 1968; Wolpe \& Lang, 1974) as well as expert information from entomologist specialists and students. It has 46 arthropod items where the respondent has to rate (yes/no) whether they know, fear and feel disgust with the arthropods. Content validity of this newly created survey questionnaire in Malay language was performed by entomologist and psychology experts. In order to determine the questionnaire validity, exploratory factor analysis was conducted on fear of arthropods survey items to confirm the number of factors, while the questionnaire reliability was acquired from the Cronbach alpha value (.90). Data were inspected for normality and analysed using SPSS Version 20. One-way ANOVA and chi-square were used to determine the differences between gender and types of arthropods. The $p$-value of $<0.05$ was used in this study.

\section{Results and discussion}

A total of 224 UKM students participated in this study. They consisted of 26 (11.6\%) male students and $198(88.4 \%)$ female students. Majority of the respondents are Malay with 174 (77.7\%), followed by Chinese 34 (15.2\%), Indian 10 (4.5\%) and others 6 (2.7\%). About 162 (72.6\%) individuals had experienced being stung or bitten by insects; $52 \%$ of the students came from urban areas, $31 \%$ from semi urban and $16 \%$ from rural areas.

Based on Figure 1, arthropods that were feared by more than half of the respondents: scorpion ( $83.0 \%$ of the respondents), wasp $(78.3 \%)$, centipede $(75.1 \%)$, bee $(73.1 \%)$, blister beetle $(63.1 \%)$ and cockroach $(52.0 \%)$.

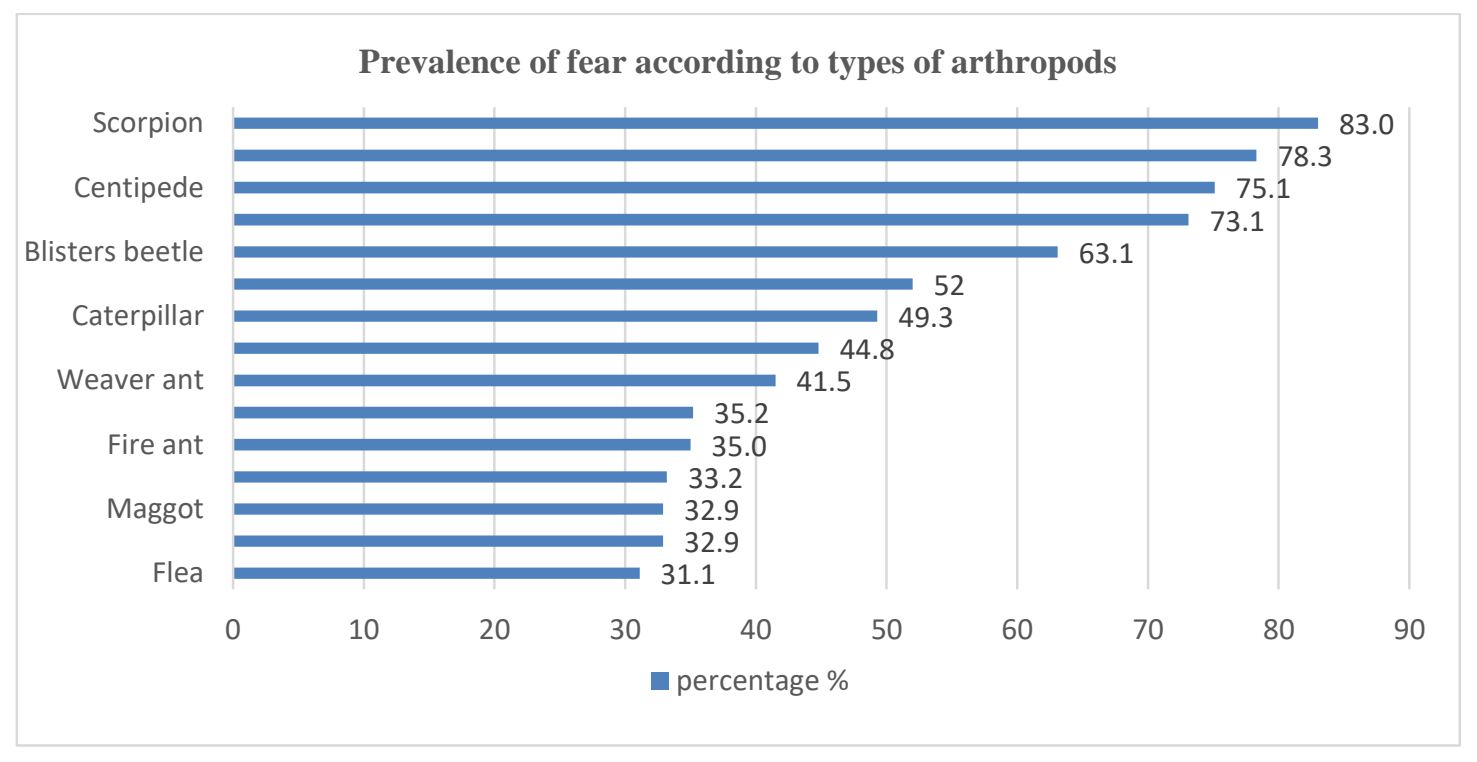

Figure 1. The prevalence of fear according to types of arthropods

This finding was supported by previous finding that showed that an association between entomophobia and size of insects in their Knowledge, Attitude and Practice (KAP) study 
(Firoozfar et al., 2012). Arthropods that are easier to be seen and noticed elicited more fear compared to smaller ones, as indicated in our study in which flea (average size of $2 \mathrm{~mm}$ ) has the lowest percentage of fear arousal (31.1\%) compared to most arthropods (Figure 1). Although the smaller scabies mite (size of less than $0.5 \mathrm{~mm}$, almost unnoticeable with naked eyes) is slightly more feared by the respondents $(35.2 \%)$ but this phenomenon might be associated with scabies, the disease, which causes skin lesions and irritation. Arthropods found disgusting by more than half of the respondents were: maggot $(80.7 \%)$, cockroach $(67.7 \%)$, caterpillar $(56.3 \%)$, centipede $(55.3 \%)$, sago larvae $(53.8 \%)$ and head lice $(52.5 \%)$ (Figure 2$)$.

'Creepy-crawlies' (defined as small arthropods that gives a feeling of fear and dislike) can be perceived as invading one's privacy, for instance bed bugs which was shown to cause disgust in almost $40 \%$ of our respondents. A few studies have shown a correlation between fear and disgust using different self-report of disgust and fear in spider (Mulkens et al., 1996; Olatunji \& Deacon, 2008). Based on structural regression analysis, it is found that college students have high fear of spiders than non college students; this correlated with greater disgust during exposure to fake spider (Olatunji \& Deacon, 2008). Similarly, we also found that both cockroach and centipede scored more than $50 \%$ of prevalence for fear and disgust, suggesting an association between the two emotions. In addition to cockroach and centipede, our respondents feared mostly on scorpion and were highly disgusted with maggot.

Fear of scorpion and wasp could be due to perception of the arthropods being dangerous and as cause of envenomation (Alexander, 1984; Vetter et al., 2018). Fear of cockroach might be caused by its ability to fly using its membranous hind wings. A flying cockroach, especially a larger-sized one, could alarm and cause people to jump. Study showed that disgust to maggot is due to its repulsive nature (Alexander, 1984; Vetter et al., 2018), while disgust to cockroach might be due its eating, regurgitating and defecating behaviors. Being an omnivorous animal, cockroaches not only eat food, but also non-food items including faeces, blood, shoes and books, making them a suitable mechanical vector for transmission of intestinal protozoa, helminthes, viruses and bacteria. The fact that they regurgitate what they eat also contributes to the transmission. Cockroach excreta can be found in a heavily infested house usually with accompanying strong malodorous smell. Further, cockroach was seen as dangerous and a cause of fear due to its disgusting nature and ability to spread disease (Jose, 2019).

Centipede is feared because its ability to sting and introduce venom to its victim using poison claws (i.e., the modified first pair of legs). This can cause injury and pain to the victim. Disgust toward it might be caused by its fast-moving, slithering movement and worm-like, multiple legs appearance. The top-five most feared arthropods are classified as venomous arthropods except blister beetle which may be classified as poisonous due to its blister-inducing body fluid.

Maggot, caterpillar and sago larva are among the top-five most disgusting arthropods and these are larval stages of flies, butterflies and beetles respectively. People are disgusted by maggot because of its association with dirtiness, garbage and also death. This is supported by disgust toward adult flies including house fly and blowfly (Figure 2). Caterpillar is always associated with itchiness. Meanwhile, sago larvae (also known as sago grub) are a delicacy in some Malaysian communities (Chung et al., 2002). Certain individuals are disgusted by sago larvae as food and cannot bear watching other people eating it. 


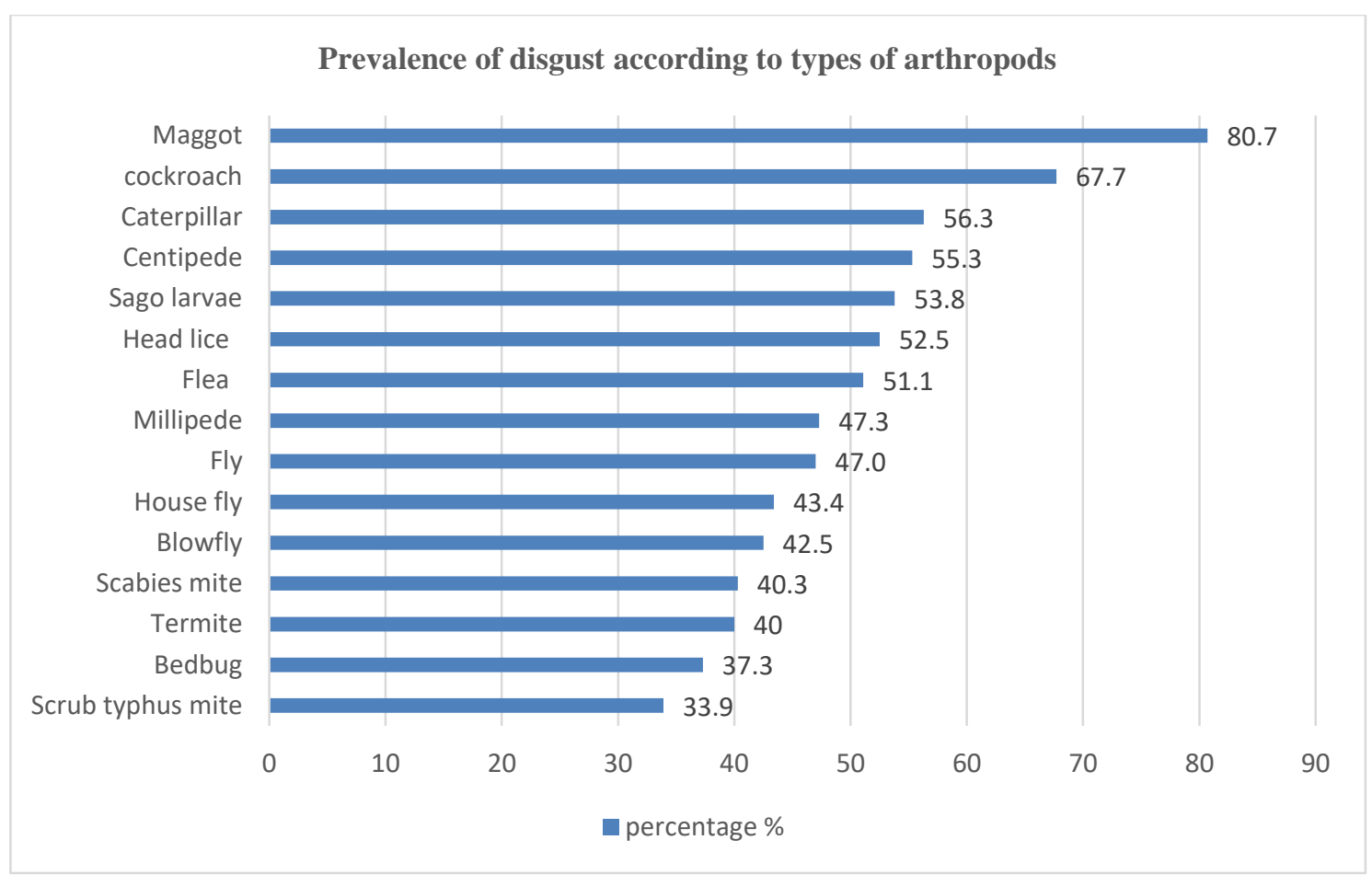

Figure 2. The prevalence of disgust according to types of arthropods

Unlike studies from European countries and the United States of America, spiders are not the commonest source of fear in our study. Instead, scorpion showed the highest prevalence of fear $(82.3 \%)$. The reasons for this are yet to be investigated. It might be rooted in more frequent encounters or interactions with scorpion either face-to-face or from any printed or electronic medium. Nonetheless, fear of scorpion is still categorised as arachnophobia (defined as fear of arachnids including spiders and scorpions). Research about scorpion remains unexplored in Malaysia and this provides future research opportunities for local and foreign researchers.

In our study, fear and disgust toward mosquitoes had a low prevalence of $12.4 \%$ and $15.1 \%$ respectively (not shown in the graphs). Unlike Zika, mosquito-borne diseases such as dengue and chikungunya are endemic and locally transmitted in Malaysia. Even though considerable numbers of deaths were reported from dengue cases each year in Malaysia the students may have become accustomed to hearing about dengue and to acquiring mosquito bites (iDengue, 2020).

Figures 3 and 4 summarise the fear and disgust of each gender according to types of arthropods. These two figures showed higher percentages of fear and disgust shown in females compared to males for all fifteen arthropods. 
GEOGRAFIA Online ${ }^{\text {TM }}$ Malaysian Journal of Society and Space 17 issue 1 (69-80)

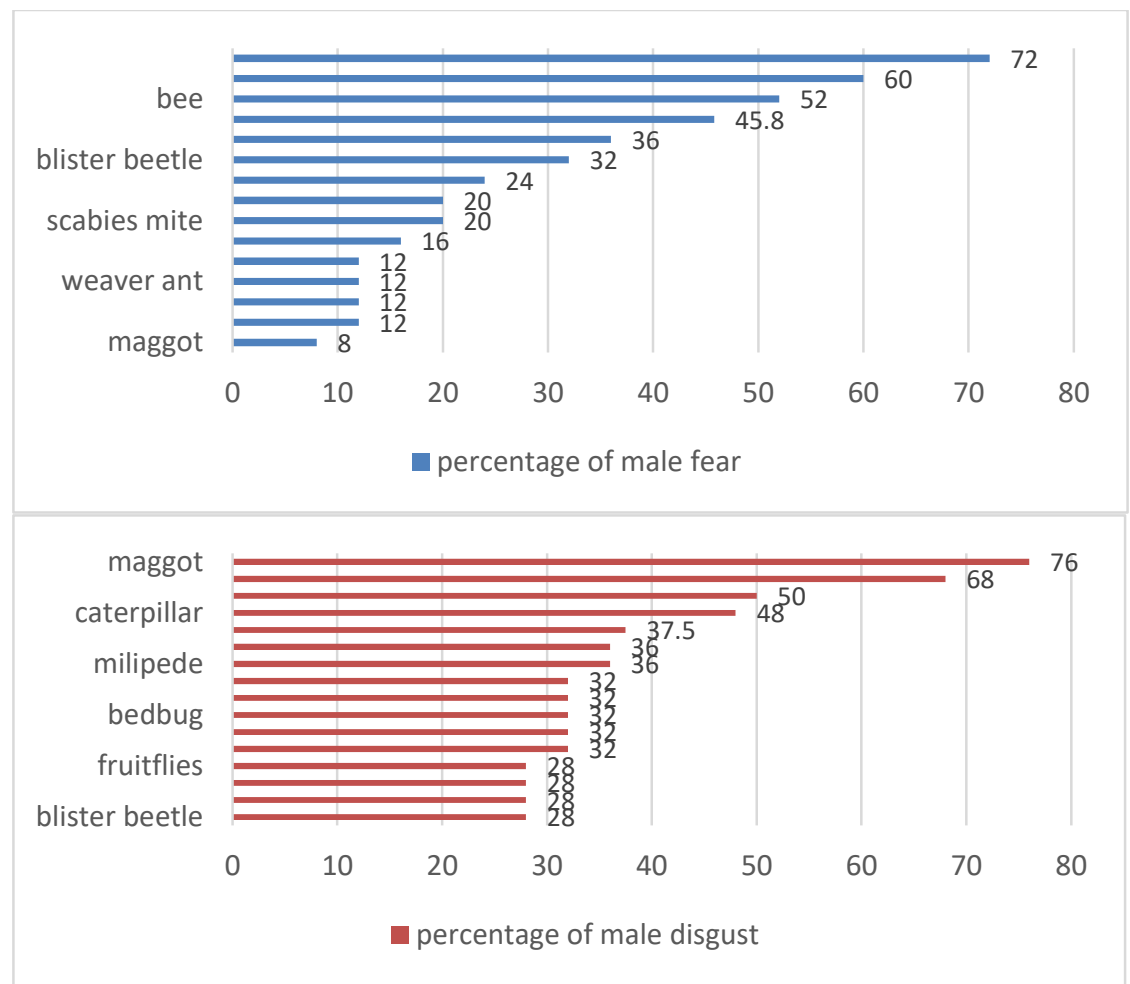

Figure 3. Percentage of male fear and disgust according to each arthropod

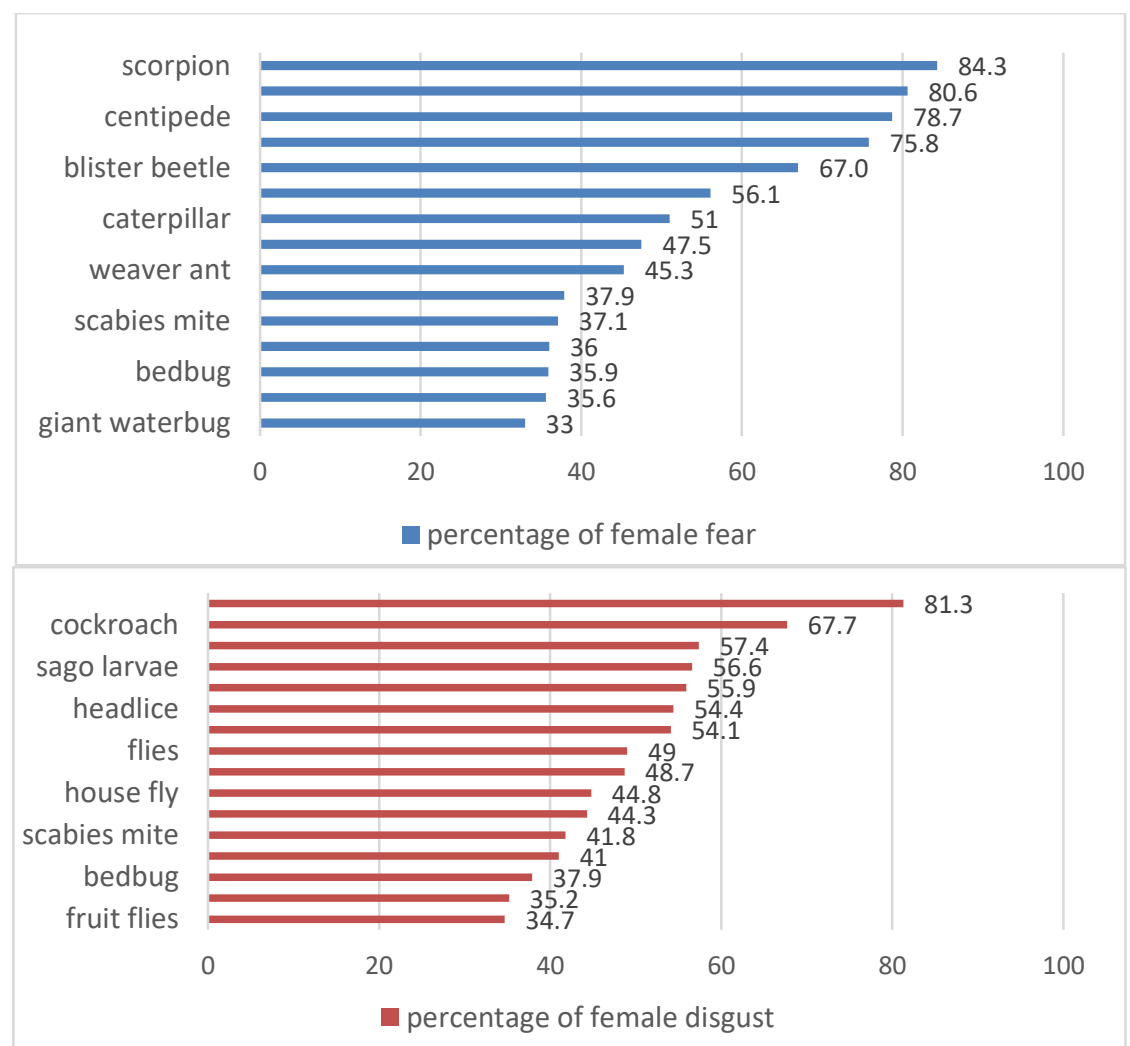

Figure 4. Percentage of female fear and disgust according to each arthropod 
The hypothesis is that females are more fearful toward arthropods as compared to males. In order to prove this, chi square test was implemented. Findings revealed that 11 out of 15 arthropods show statistically significant differences with $p$ values of less than 0.05 . This proves that females were afraid of the 11 arthropods compared to males. The exception was seen for scorpion, caterpillar, scabies mite and giant water bug that showed no difference between males or females in terms of fear toward insects with $p$ values of more than 0.05 . Table 1 summarises these findings, which indicating that both genders can significantly differ in prevalence of fear toward most arthropods.

Table 1. Gender differences on fear of arthropods

\begin{tabular}{lll}
\hline Variables & $\mathbf{X}^{\mathbf{2}}$ value & $\boldsymbol{p}$ value \\
\hline Scorpion & 1.599 & 0.20 \\
Wasp & $\mathbf{5 . 5 4 1}$ & $\mathbf{0 . 0 1}$ \\
Centipede & $\mathbf{1 2 . 3 4 8}$ & $\mathbf{0 . 0 0}$ \\
Bee & $\mathbf{6 . 3 7 1}$ & $\mathbf{0 . 0 1}$ \\
Blister beetle & $\mathbf{1 1 . 6 7 0}$ & $\mathbf{0 . 0 0}$ \\
Cockroach & $\mathbf{1 1 . 5 6 5}$ & $\mathbf{0 . 0 0}$ \\
Caterpillar & 2.001 & 0.16 \\
Spider & $\mathbf{4 . 9 4 5}$ & $\mathbf{0 . 0 3}$ \\
Weaver ant & $\mathbf{1 0 . 1 1 3}$ & $\mathbf{0 . 0 0}$ \\
Scabies mite & 2.845 & 0.09 \\
Fire ant & $\mathbf{6 . 5 3 6}$ & $\mathbf{0 . 0 1}$ \\
Bedbug & $\mathbf{5 . 7 0 8}$ & $\mathbf{0 . 0 2}$ \\
Maggot & $\mathbf{7 . 9 0 4}$ & $\mathbf{0 . 0 1}$ \\
Giant water bug & 2.991 & 0.08 \\
Flea & $\mathbf{5 . 5 7 4}$ & $\mathbf{0 . 0 2}$ \\
\hline
\end{tabular}

Different findings were found for disgust in which only two arthropods have $p$ values of less than 0.05 , which are sago larvae and flea that were found disgusting by female students. Table 2 summarises these findings, indicating that both genders can be similarly affected by disgust depending on the types of arthropods based on the $p$ values of more than 0.05 in 13 out of 15 arthropods.

Table 2. Gender differences on disgust toward arthropods

\begin{tabular}{lll}
\hline Variables & $\mathbf{X}^{\mathbf{2}}$ value & $\boldsymbol{p}$ value \\
\hline Maggot & 0.134 & 0.715 \\
Cockroach & 0.001 & 0.974 \\
Caterpillar & 0.790 & 0.374 \\
Centipede & 0.301 & 0.583 \\
Sago larvae & $\mathbf{5 . 4 1 3}$ & $\mathbf{0 . 0 2 0}$ \\
Head lice & 2.436 & 0.119 \\
Flea & $\mathbf{6 . 0 4 9}$ & $\mathbf{0 . 0 1 4}$ \\
Millipede & 1.442 & 0.230 \\
Fly & 2.560 & 0.110 \\
Horse fly & 1.488 & 0.223 \\
Blow fly & 2.417 & 0.120 \\
Scabies mite & 1.765 & 0.184 \\
Termite & 0.752 & 0.386 \\
Bedbug & 0.335 & 0.563 \\
Scrub typhus mite & 1.241 & 0.265 \\
\hline
\end{tabular}


One factor thought to cause fear of insects is experience of being stung/bitten by that particular arthropod. To prove the hypothesis, a total of 15 most feared arthropods were analysed using Chi square. The result shows only spider bite showed significant difference with a $p$ value of 0.04, supporting that there is a relationship between fear and spider bite experience. The rest of arthropods show no relationship between fear and history of bite/sting. Fear of spiders and other arthropods had been reported to occur more frequently in females than males which are in line with our study (Shahriari-Namadi et al., 2018). However, this preponderance might be due to the fact that our female respondents comprised $88.4 \%$ out of the total respondents. In contrast to disgust, two arthropods have $p$ value less than 0.05 , which are sago larvae and flea that were disgusted by female students. Table 3 summarises these findings, which indicates that both genders can be similarly affected by disgust depending on the types of arthropods.

The present finding was supported by previous finding (Curtis et al., 2004) indicating females showed high disgust sensitivity than males. The present study showed that flea is not only found fearful but also disgusted by female participants than male. In other disgust study, they found that photos of head lice and Ascaris worms are more disgusting than wasp and caterpillar (Curtis et al., 2004). Participants reported feeling both fearful and disgusted toward spider in another study (Thorpe \& Salkovski, 1998). Thorpe and Salkovski (1998) stated the general feelings of disgust were intensified by feeling fear that leads to avoidance of insect. However, feeling disgusted did not contribute to fear of insects (entomophobia) unless feeling disgust was amplified by feeling fearful by insects. Some researchers believe that disgust emotion can be evoked by feeling threats of infectious disease (Curtis et al., 2004), sickness and contamination (Thorpe \& Salkovskis, 1998).

In addition, no differences were found between fear and disgust toward arthropods and living areas (urban, semi urban and rural). Rural residents are thought to be more prepared to come across insects and other arthropods, especially if they had frequent encounters with the animals previously or have a more open-space living area which enables the creatures to make their way in or out of houses. However, we cannot prove this based on our analysis.

We have not yet explored the specific reasons why the student respondents have fear toward insects which can be further investigated. Research also could be extended to different populations including school-aged children, patients with mental disorders and the general public. Similar proportions of males and females could be recruited to investigate the role of gender in greater depth.

\section{Conclusion}

In conclusion, fear and disgust of scorpion, wasp, bees and other arthropods are prevalent among Malaysian university students. These findings help therapy-related practitioners prepare themselves in advance by knowing the commonest arthropods that might induce fear and/or disgust in patients. There is a saying that we fear what we do not understand or we fear the unknown. Understanding and information about these arthropods help people to not only avoid or fear insects but care and foster them for better biodiversity and ecological environment. Education and information play a pivotal role in this matter. Activities such as tours to insect exhibitions in museums, forest trips to observe insects as wildlife can be curated for the children. In Malaysia, Zoo Negara and Taman Rama-Rama should be applauded for their initiatives of having specific parks and exhibitions for insects and other arthropods. Visit to Forest Research Institute Malaysia 
(FRIM) as the centre of reference for insect taxonomic studies, or having National Insect Day by entomological societies with exhibition targeted to the public or through media should be conducted to not only to reduce fear but also increase knowledge on arthropods especially among school children and parents. Entomological workshops, short and full courses could also be attended by university students to increase their knowledge and understanding about the importance of insects in varied types of environments. Basic training on genus or species identification of medically important arthropods offers the skills to differentiate between venomous and non-venomous arthropods. In addition, first aid training on how to manage arthropod bites and stings can be incorporated in courses for people that require them to do work in natural habitats of the insects.

\section{Acknowledgement}

We want to acknowledge Faculty of Medicine and Universiti Kebangsaan Malaysia (UKM) for permission to conduct our survey (Project Code: FF-2019-516). Also, we thank the staff and postgraduate students of the Department of Parasitology and Medical Entomology and Department of Psychiatry, Faculty of Medicine, UKM for their assistance. We convey our gratitude to the respondents for their consent and cooperation in participating in this study.

\section{References}

Alexander, J. (1984). Centipede bites and millipede burns. In J. O. Alexander (Ed.), Arthropods and human skin (pp. 383-389): Berlin, Germany: Springer-Verlag.

Armfield, J. M. (2007). Understanding animal fears: a comparison of the cognitive vulnerability and harm-looming models. BMC Psychiatry, 7(1), 68. doi:10.1186/1471-244X-7-68

Berenger, J., \& Parola, P. (2016). Arthropod vectors of medical importance. In J. Cohen, W. G. Powderly \& S. M. Opal (Eds.), Infectious diseases (4th ed., pp. 104-112). New York: Elsevier. https://doi.org/10.1016/B978-0-7020-6285-8.00012-5

Breed, M., \& Sanchez, L. (2010). Both environment and genetic makeup influence behavior. Nature Education Knowledge, 3(10), 68.

Burgess, N. R. H., \& Cowan, G. O. (1993). A Colour Atlas of Medical Entomology. Dordrecht: Springer Netherlands.

Cavallo, C., \& Materia, V. C. (2018). Insects or not insects? Dilemmas or attraction for young generations: A case in Italy. International Journal on Food System Dynamics, 9(3), 226239.

Chen, X., Feng, Y., \& Chen, Z. (2009). Common edible insects and their utilization in China. Entomological Research, 39(5), 299-303.

Chung, A. Y. C., Khen, C. V., Unchi, S., \& Binti, M. (2002). Edible insects and entomophagy in Sabah, Malaysia. Malayan Nature Journal, 56(2), 131-144.

Curtis, V. (2011). Why disgust matters. Philosophical Transactions of the Royal Society B: Biological Sciences, 366(1583), 3478-3490.

Curtis, V., Aunger, R., \& Rabie, T. (2004). Evidence that disgust evolved to protect from risk of disease. Proceedings of the Royal Society of London. Series B: Biological Sciences, 271(suppl_4), S131-S133. 
Davey, C. L. (1993). Factors influencing self-rated fear to a novel animal. Cognition and Emotion, 7(5), 461-471. doi:10.1080/02699939308409199

Firoozfar, F., Norjah, N., Baniardalani, M., \& Moosa-Kazemi, S. (2012). Knowledge, attitudes and practices study in relation to entomophobia and its application in vector-borne-diseases. Asian Pacific Journal of Tropical Biomedicine, 2(2, Supplement), S1135-S1137. doi:https://doi.org/10.1016/S2221-1691(12)60373-6

Gaston, K. J. (1992). Regional Numbers of Insect and Plant Species. Functional Ecology, 6(3), 243-247. doi: $10.2307 / 2389513$

Geer, J. H. (1965). The development of a scale to measure fear. Behaviour research and therapy, $3(1), 45-53$.

Gerozisis, J., Hadlington, P. \& Staunton, I. (2014). Urban Pest Management in Australia (5th ed.). Sydney NSW: UNSW Press.

Goddard, J. (2008). Infectious Diseases and Arthropods. Springer.

Gullan, P. J., \& Cranston, P. S. (2014). The importance, diversity and conservation of insects. In The insects: An outline of entomology (pp. 1-7). West Sussex: W Blackwell.

Hanboonsong, Y. (2010). Edible insects and associated food habits in Thailand. Forest insects as food: humans bite back, 173, 182.

Hardy, T. N. (1988). Entomophobia: the case for Miss Mufet. Bulletin of the ESA, 34(2), 64-69.

Hayati, D., \& Minaei, K. (2015). Investigation of entomophobia among agricultural students: The case of Shiraz University, Iran. Journal of Entomological and Acarological Research, 47(2), 43-45.

iDengue. (2020). Statistik Denggi. http://idengue.arsm.gov.my/page2.php?kandungan=content/ statistik.pdf

Jose, V. (2019). Why are humans so afraid of insects? International Journal of Trend in Scientific Research and Development, 3(2), 2456-6470.

Jun, Y., Bae, S., Shin, T., Lee, S., Gwak, W., Ahn, Y., Kim, I., Lee, S., Kim, D., Kim, T., \& Woo, S. (2016). Effects of an insect-mediated mental healthcare program for mentally disordered children. Entomological Research, 46(1), 85-90. doi:10.1111/1748-5967.12149

La Barbera, F., Verneau, F., Amato, M., \& Grunert, K. (2018). Understanding Westerners' disgust for the eating of insects: The role of food neophobia and implicit associations. Food Quality and Preference, 64, 120-125.

Lockwood, J. (2013). The infested mind: Why humans fear, loathe, and love insects. Oxford University Press.

Marks, I. M. (1978). Living with fear: Understanding and coping with anxiety. McGraw-Hill.

Marks, I. M. (1987). Fears, phobias, and rituals: Panic, anxiety, and their disorders. Oxford University Press.

Morozov, A. M., \& Sherman, R. A. (2019). Survey of patients of the Tver region of Russia regarding maggots and maggot therapy. International Wound Journal, 16(2), 401-405.

Mulkens, S. A. N., de Jong, P. J., \& Merckelbach, H. (1996). Disgust and spider phobia. Journal of Abnormal Psychology, 105(3), 464.

Nowak, N., Bazan-Socha, S., Pulka, G., Pełka, K., \& Latra, P. (2015). Evaluation of the quality of life in subjects with a history of severe anaphylactic reaction to the Hymenoptera venom. Advances in Respiratory Medicine, 83(5), 352-358.

Okon-Singer, H., Alyagon, U., Kofman, O., Tzelgov, J., \& Henik, A. (2011). Fear-related pictures deteriorate the performance of university students with high fear of snakes or spiders. Stress, 14(2), 185-193. 
Olatunji, B. O., \& Deacon, B. (2008). Specificity of disgust sensitivity in the prediction of fear and disgust responding to a brief spider exposure. Journal of Anxiety Disorders, 22(2), 328-336.

Özer, N. (2005). Emerging vector-borne diseases in a changing environment. Turkish Journal of Biology, 29(3), 125-135.

Pato, J., Illera, J. C., Obeso, J. R., \& Laiolo, P. (2019). The roles of geography, climate and sexual selection in driving divergence among insect populations on mountaintops. Journal of Biogeography, 46(4), 784-795. doi:10.1111/jbi.13540

Phillips, M. L., Senior, C., Fahy, T., \& David, A. S. (1998). Disgust: The forgotten emotion of psychiatry. The British Journal of Psychiatry, 172(5), 373-375.

Rao, A. (2017). Trends of vector borne diseases in the west and likely climate impact. International Pest Control, 59(4), 202-204.

Roberts-Thomson, P. J., Harvey, P., Sperber, S., Kupa, A., \& Heddle, R. J. (1985). Bee sting anaphylaxis in an urban population of South Australia. Asian Pacific Journal of Allergy and Immunology, 3(2), 161-164.

Rubin, B. M., Katkin, E. S., Weiss, B. W., \& Efran, J. S. (1968). Factor analysis of a fear survey schedule. Behaviour Research and Therapy, 6(1), 65-75.

Schönfelder, M. L., \& Bogner, F. X. (2017). Individual perception of bees: Between perceived danger and willingness to protect. PLOS ONE, 12(6), e0180168. doi:10.1371/journal.pone.0180168

Shahriari-Namadi, M., Tabatabaei, H. R., \& Soltani, A. (2018). Entomophobia and arachnophobia among school-age children: A psychological approach. Shiraz E-Med J, 19(7), e64824. doi:10.5812/semj. 64824

Thorpe, S. J., \& Salkovskis, P. M. (1998). Studies on the role of disgust in the acquisition and maintenance of specific phobias. Behaviour research and therapy, 36(9), 877-893.

Trabert, W. (1995). 100 years of delusional parasitosis. Psychopathology, 28(5), 238-246.

Vetter, R., S., Draney, M., L., Brown, C., A., Trumble, J., T., Gouge, D., H., Hinkle, N., C., \& Pace-Schott, E., F. (2018). Spider fear versus scorpion fear in undergraduate students at five American universities. American Entomologist, 64(2), 79-82.

Vidal, M. C., Quinn, T. W., Stireman III, J. O., Tinghitella, R. M., \& Murphy, S. M. (2019). Geography is more important than host plant use for the population genetic structure of a generalist insect herbivore. Molecular Ecology, 28(18), 4317-4334. doi: $10.1111 / \mathrm{mec} .15218$

Wolpe, J., \& Lang, P. J. (1974). A fear survey schedule for use in behavior therapy. Behavior modification procedure: A sourcebook (pp. 228-232).

Yang, C., Dillard, J. P., \& Li, R. (2018). Understanding fear of Zika: Personal, interpersonal, and media influences. Risk Analysis, 38(12), 2535-2545. doi:10.1111/risa.12973 